\title{
Time-Domain Predistortion Method Based on Raised Cosine Signaling in Real Transmission Channels
}

\author{
Bretislav Sevcik \\ Faculty of Electrical Engineering and Communication, Brno University of Technology, 61600 Brno, Czech Republic
}

Correspondence should be addressed to Bretislav Sevcik, xsevci34@stud.feec.vutbr.cz

Received 8 March 2012; Revised 14 May 2012; Accepted 14 May 2012

Academic Editor: G. Ghibaudo

Copyright () 2012 Bretislav Sevcik. This is an open access article distributed under the Creative Commons Attribution License, which permits unrestricted use, distribution, and reproduction in any medium, provided the original work is properly cited.

The concept of time-domain predistortion method based on raised cosine signaling is applied in real transmission channels. The proposed PWM-RC method uses raised-cosine pulse shaping instead of conventional rectangular digital signals and pulse-width modulation (PWM) scheme to achieve better output channel data response in harsh channel environment. The conventional predistortion methods based on pulse amplitude adjusting are not compatible with modern low-power CMOS design. Currently existing time-domain predistortion methods which are only based on a PWM scheme show many highfrequency signal harmonic components for both fast and slow signal transitions. It can cause more system crosstalk susceptibility if the crosstalk is dominant factor in transmission channel. In this case, the additional preemphasis boosted undesirable high-frequency components. Finally, the real channel transfer functions in connection with ADS Agilent development studio are used to compare the performance of proposed method with other predistortion methods.

\section{Introduction}

Today's high-speed multicore microprocessors and memory interfaces require ever increasing interconnect bandwidth. Stringent requirements for a reduced board space, miniature connectors, efficient printed circuit board (PCB) design, and low susceptibility to noise are associated with the serial communications links architecture. Many existing serial I/O standards operate at multi-Gbps speeds such as well-known PCI Express (PCIe). Next generation of the standard PCIe Gen 3 is able to operate at $8 \mathrm{Gbps}$ in a single lane. As data rates are increasing, their susceptibility to damage is more critical. It is caused by the nonideal aspects of transmission lines, such as crosstalks and losses as well as energy dissipation caused by reflections and radiation [1]. All these issues can cause significant problems in signal integrity and timing. In such severe environments, sophisticated pulse-shaping techniques such as the equalization or preemphasis (equalization at the transmitter is often called transmitter preemphasis to reflect the effect of the filter operation) need to be employed to increase the data rates
[2]. In this paper, for the first time the PWM-RC (raised cosine) predistortion method is applied in real transmission channels; see Figure 1.

The concept of proposed signaling method is briefly described in [3]. It is shown that PWM-RC method significantly reduces the high-frequency content in pre-distorted high-speed signals. The concept of PWM signaling scheme is proposed in [4] and is applied to the coaxial cable loss equalization and simple single PCB trace equalization. It is shown that the PWM preemphasis provides higher maximum loss compensation $(24 \mathrm{~dB})$ than the commonly used 2-tap FIR filter $(18 \mathrm{~dB})$. The transfer function of PWM method is able to provide a better adaptation to the copper channel; see results in Agilent ADS [5]. However, the implementation of the predistortion methods based on pulse amplitude shaping can be significantly restricted by noise margin because modern low-voltage CMOS devices use supply voltage, which will decrease according to CMOS scaling [6]. However, the crosstalk susceptibility of conventional PWM scheme based on rectangular pulse shaping can cause additional high-frequency content in equalized data 


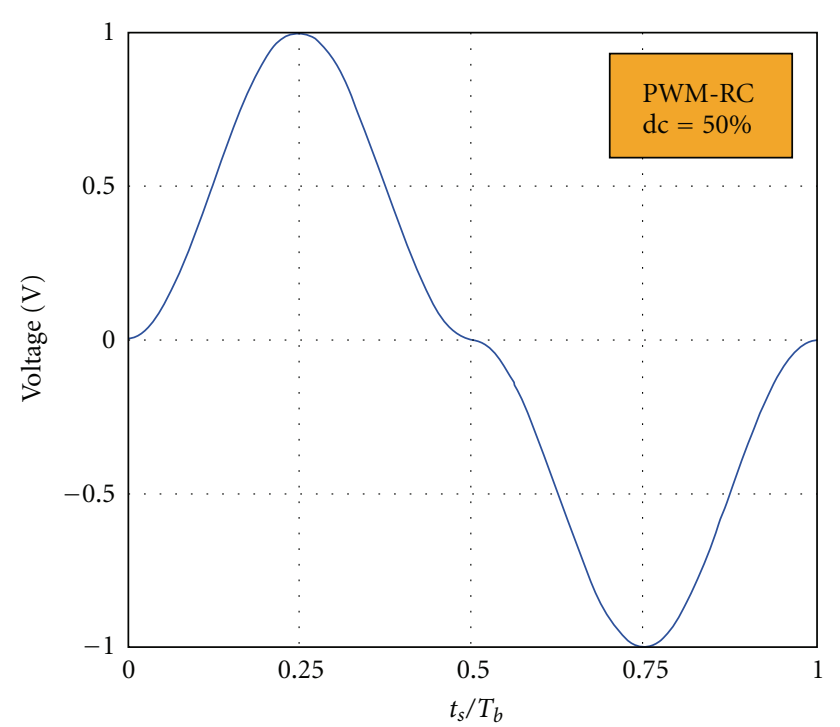

(a)

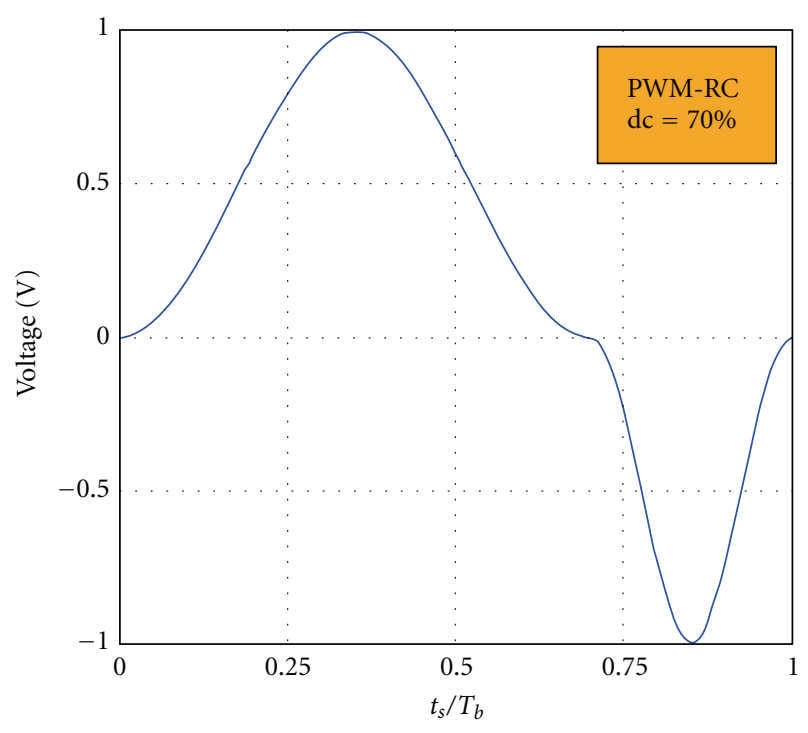

(b)

FIgURE 1: PWM-RC signal shaping.

stream. Thus, the loss compensation can be significantly reduced. The combination of PWM predistortion technique and appropriate pulse shaping method (PWM-RC method) can provide an effective reduction of high-frequency components of the pulses. It is shown in [3] that the equalized channel transfer functions, when the PWM-RC method is used, have the better performance at higher frequencies due to the additional variability to adjust high frequency loss compensation. It can play a critical role for optimal preemphasis design. The experimental results presented in this paper were obtained by using the interaction between the Agilent E5071C Network analyzer and Agilent ADS Studio. Thus, the real channel transfer functions can be used together with proposed PWM-RC signaling scheme.

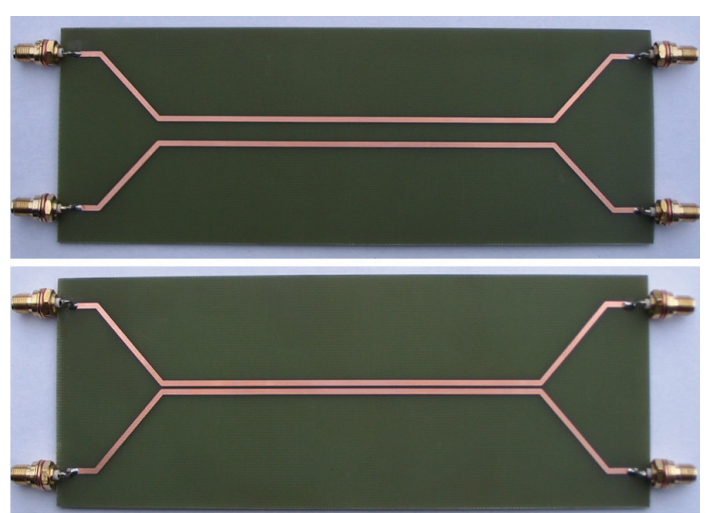

Figure 2: Two experimental analyzed $30 \mathrm{~cm}$ long backplanes.

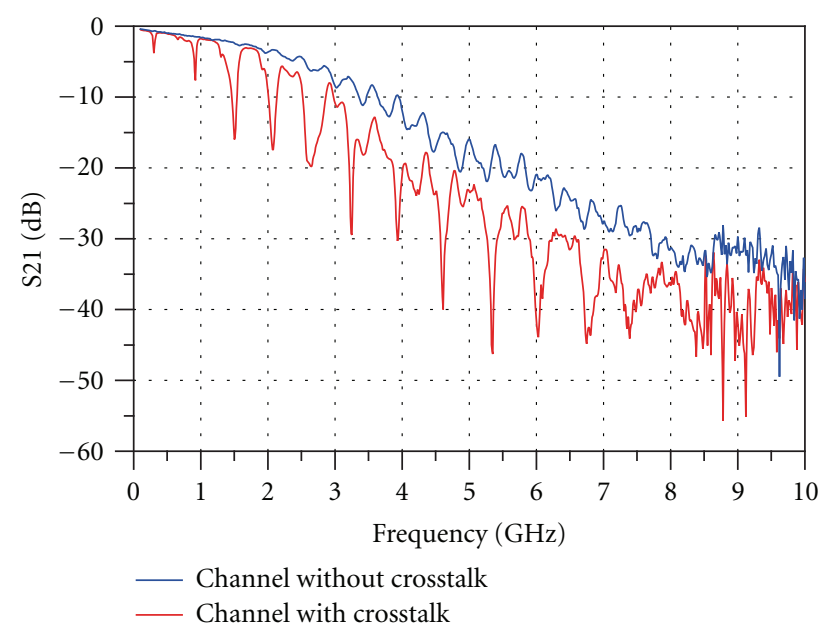

Figure 3: Transfer functions of both analyzed experimental channels.

\section{Channel Properties}

In this case two experimental $30 \mathrm{~cm}$ long backplanes for transfer function analysis are used. These backplanes were created within diploma thesis [7]; see Figure 2.

The first backplane prototype was designed with relatively large distance between transmission lines, $d=6 \mathrm{~mm}$. In this case the microstrip conductor and dielectric losses are dominant factors that must be taken into account. The second backplane prototype is designed with significant distance reduction between transmission lines, $d=0.5 \mathrm{~mm}$. In this case a significant crosstalk effect which should be taken into account in real communication systems occurs. This situation is clearly seen in Figure 3 where transfer functions (S21 parameters) for both channels are shown. It is obvious that significant high slopes can occur when crosstalk channel is analyzed. Moreover, the second backplane has intentional disturbance in GND layer. Thus, the effect of vias impact can be imitated.

Some of the final channel output eye diagrams for both measured channels are shown in Figure 4. It is obvious that the data signal passing through the crosstalk channel has almost the same performance as data signal with double data 
TABLE 1: Eye diagram performance for both channels.

\begin{tabular}{|c|c|c|c|c|}
\hline \multirow{2}{*}{$\begin{array}{l}\text { Data rate } \\
\text { (Gbps) }\end{array}$} & \multicolumn{2}{|c|}{ No crosstalk } & \multicolumn{2}{|c|}{ Crosstalk } \\
\hline & $\begin{array}{l}\text { Eye height } \\
(\mathrm{mV})\end{array}$ & $\begin{array}{l}\text { Eye width } \\
\text { (ps) }\end{array}$ & $\begin{array}{l}\text { Eye height } \\
(\mathrm{mV})\end{array}$ & $\begin{array}{l}\text { Eye width } \\
\text { (ps) }\end{array}$ \\
\hline 1 & 163.9 & 979.9 & 103.1 & 689.2 \\
\hline 2 & 154.1 & 475.6 & 95.2 & 328.2 \\
\hline 3 & 142.2 & 362.2 & 88.7 & 278.2 \\
\hline 5 & 78.3 & 198.1 & 6.2 & 110.2 \\
\hline 6 & 57.6 & 140.9 & \multicolumn{2}{|c|}{ Eye closed } \\
\hline 8 & \multicolumn{2}{|c|}{ Eye closed } & \multicolumn{2}{|c|}{ Eye closed } \\
\hline 10 & \multicolumn{2}{|c|}{ Eye closed } & \multicolumn{2}{|c|}{ Eye closed } \\
\hline
\end{tabular}

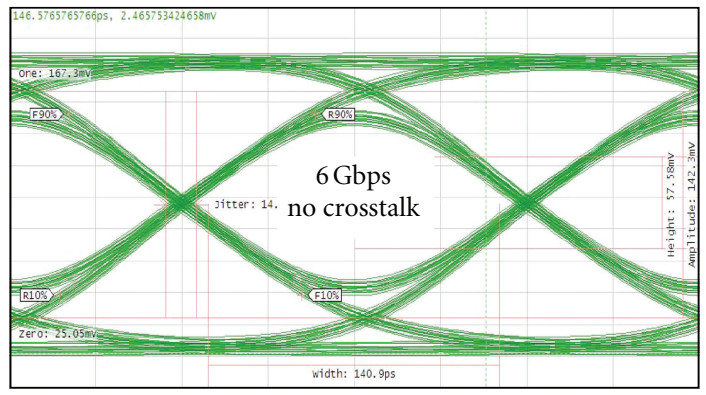

(a)

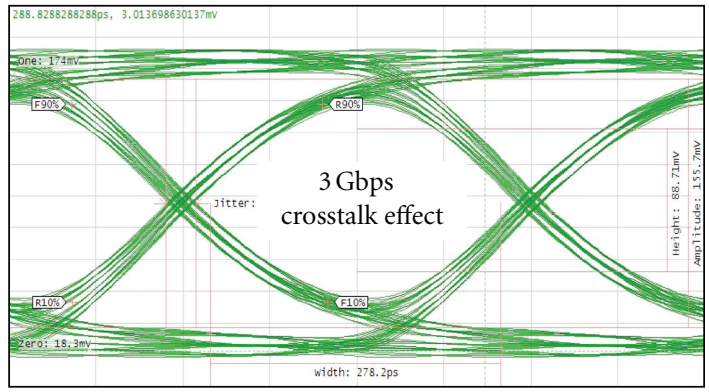

(b)

Figure 4: Example of eye diagram results for both analyzed channels.

rate for channel without crosstalk and GND disturbance. The experimental measurements are summarized in Table 1 where the significant differences between both analyzed channels are noticeable. Voltage amplitude is set to $200 \mathrm{mV}$.

In this case it is necessary to use a sophisticated method for signal conditioning. The simulations results realized in MathCAD show significant increase in crosstalk for relatively long coupling lengths (this corresponds with realized backplane prototypes measurements) and decreasing in aggressor distance; see [8]. The aggressor represents separated singleended circuit with the random bit sequences and the same data rate as victim circuit.

\section{Preemphasis Performance}

In [3] it is shown significant high-frequency component reduction for the proposed PWM-RC predistortion method.

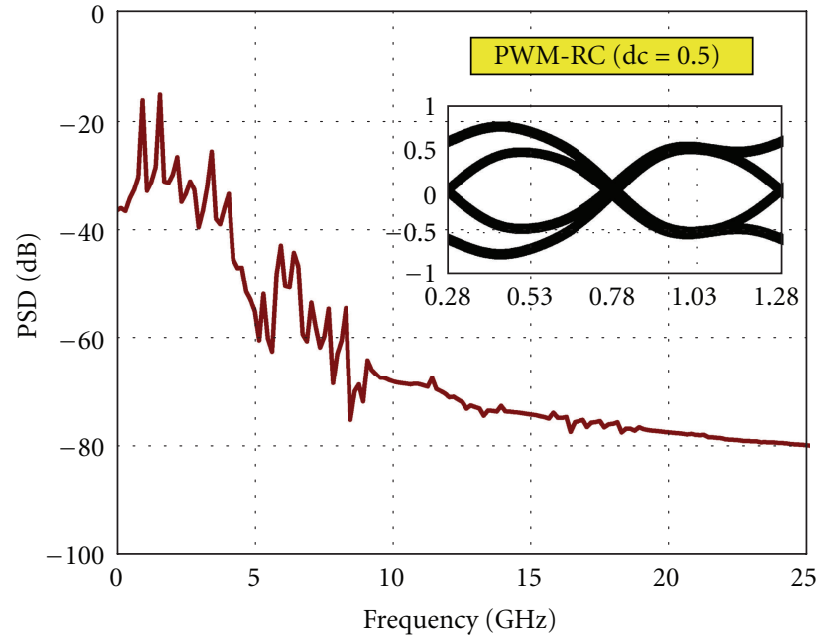

(a)

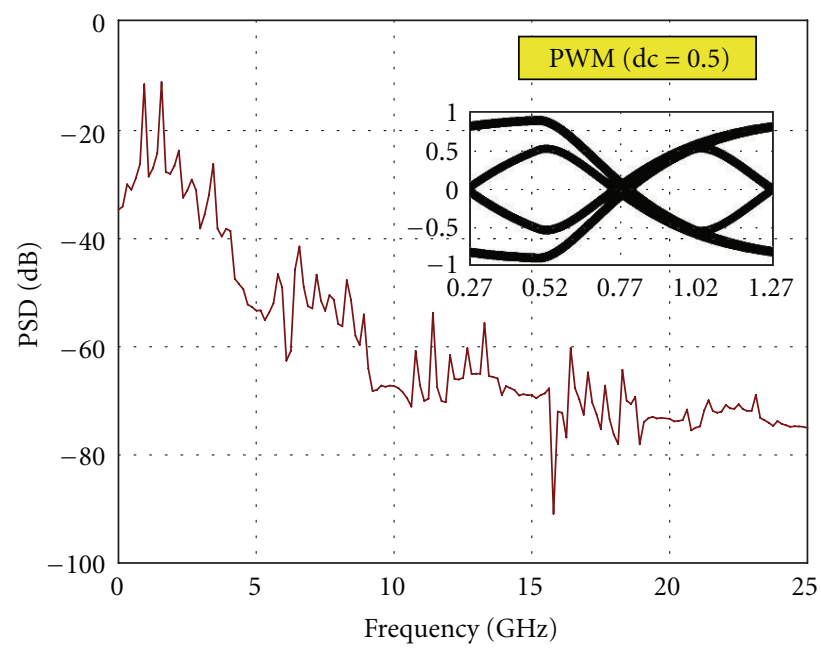

(b)

FIGURE 5: Signal spectrum analysis at the transmitter output, 5 Gbps data rate.

The power spectral density (PSD) analysis results are shown in Figures 5 and 6. In both cases, the conventional PWM method with proposed PWM-RC method is compared for the same dc (duty-cycle) settings. In the first case the signal spectrum is analyzed at the transmitter output without additional transmission lines effects. Especially the near end crosstalk (NEXT) at the connectors can be amplified by additional high-frequency content. In Figure 5 the maximum preemphasis effect is set. The proposed method significantly reduces high-frequency harmonic components of preemphasized data signal. In this case at frequency $10 \mathrm{GHz}$ the second signal harmonic is considered. Compare both eye diagrams shaping where a random bit sequence is analyzed.

The main disadvantage of conventional preemphasis methods is described in [3]. The strong susceptibility to crosstalk is evident $[4,6]$. In [6] by using a simple Fourier series calculation it is shown that the output spectrum of 


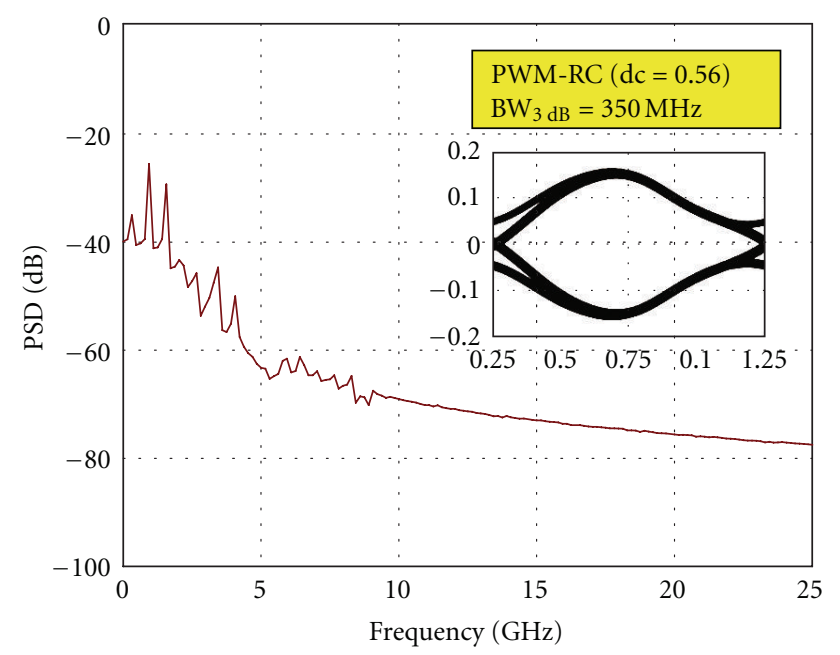

(a)

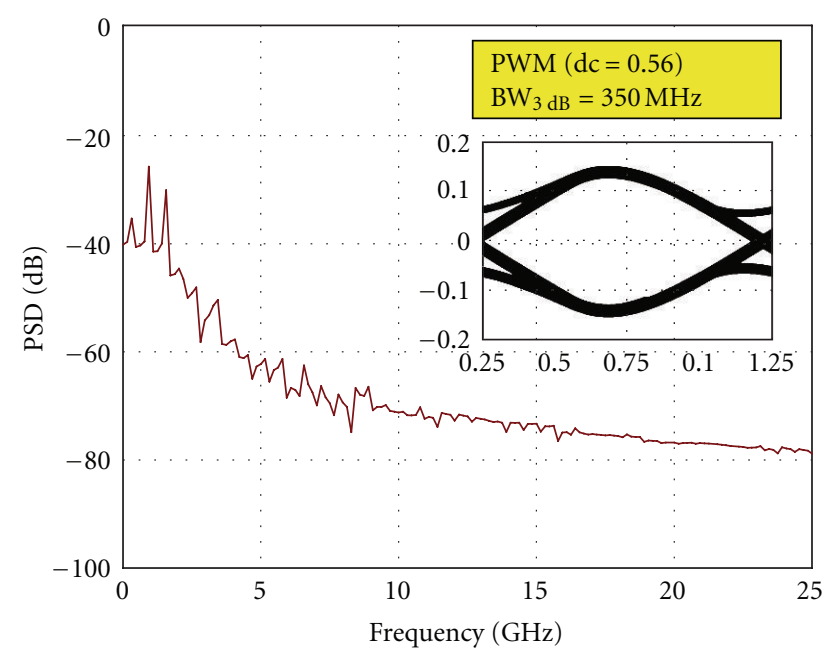

(b)

FIGURE 6: Signal spectrum analysis at the channel output, 5 Gbps data rate.

conventional filter exhibits more high-frequency components if low-frequency (LF) pattern (transmitting many l's in succession) is transmitted. It can cause complications if channel which has been equalized is predisposed to crosstalk formation. In Figure 6 the frequency spectrum analysis at the band-limited channel output for both PWM methods is shown. In this case the optimal preemphasis setting is selected. The real random high-speed $5 \mathrm{Gbps}$ data stream is formed. The proposed PWM-RC method still reduces high-frequency harmonic components at channel output but many high-frequency components are absorbed by the channel itself. The simulated LF pattern was transmitted over the band-limited channel too. The significant reduction in high-frequency components is seens; each of the figures show one bit period where on $x$ axis the bit period is shown. It can be concluded that the proposed PWM-RC scheme is able to sufficiently compensate the additional highfrequency components also for lower switching frequency. This behavior is close to conventional FIR filter where the

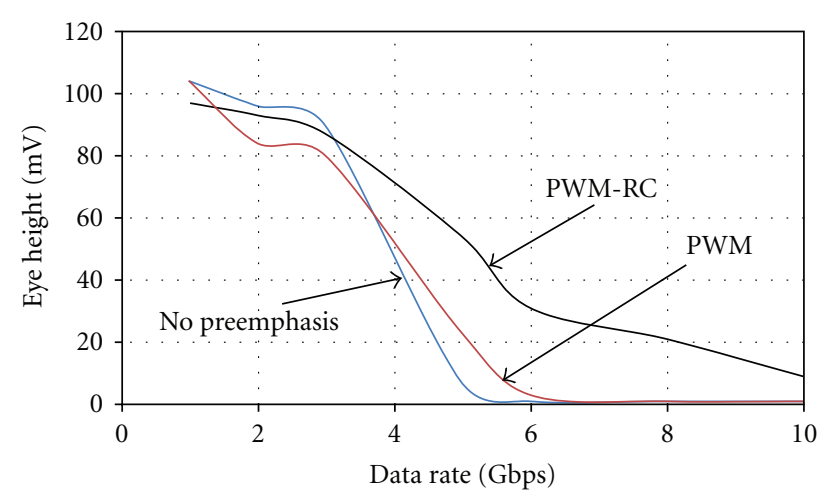

(a)

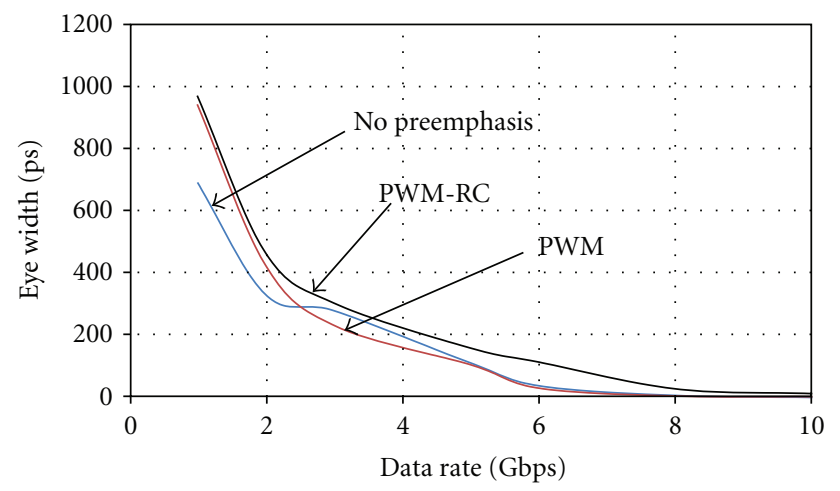

(b)

Figure 7: Eye diagram opening analysis for various data rates if crosstalk channel is used.

filter exhibits less power for lower switching frequency. For the HF pattern the difference between FIR and PWM scheme is only in phase (time shift) [4].

Finally, the PWM-RC signaling scheme was implemented in Agilent ADS simulation environment. The measured channel transfer function was used as channel environment for both PWM and PWM-RC method testing. Both main eye diagram parameters are analyzed in Figure 7. It is obvious that PWM-RC method improves eye diagram opening. Significant high slopes occur approximately at Nyquist frequencies for 3, 4, 5, and so forth, Gbps data rate. The data rate is analyzed from $1 \mathrm{Gbps}$ to $10 \mathrm{Gbps}$ with step $1 \mathrm{Gbps}$. However the main decisive factor is the average value of losses around the observed Nyquist frequencies. In this case the additional $6 \mathrm{~dB}$ loss is sufficient to completely close the eye. Note that the $6 \mathrm{~dB}$ rule is independent of voltage swing and frequency. This can be seen at Nyquist frequency $2.5 \mathrm{GHz}$ (5 Gbps data rate) where approximately $6 \mathrm{~dB}$ channel loss occurs. The significant eye closing is evident; see Figure 7. What does depend on frequency is where the $6 \mathrm{~dB}$ loss point actually occurs. One of the decisive parameters for system reliability is a receiver sensitivity that can be used to calculate a transmitted voltage swing. The signaling power can be expressed as [4]. The expression shows that the minimum transmitted signal swing depends on the receiver sensitivity and the channel's frequency response [9]. In our case, the signal swing requirement assumes intersymbol 
interferences (ISI) compensation by equalization techniques such as preemphasis at the transmitter, ideally for minimum bit error rate (BER) which is typically $10^{-9}-10^{-14}$.

\section{Conclusion}

In this paper the perspective digital time-domain predistortion technique based on the pulse-width modulation scheme and using the raised cosine signaling (PWM-RC) is analyzed in real transmission channels. In the main part of the paper, the proposed PWM-RC method and conventional PWM method are compared. It is shown that the proposed PWM-RC scheme is capable to open eye more than conventional PWM signaling scheme if channel crosstalk occurs. The signal spectrum analysis results show highfrequency content for PWM scheme especially if channel effect is not considered. The frequency-domain analysis [3] shows better performance of proposed method for the equalization of transmission channels where the attenuation is not monotonically increasing. Additional variability to adjust high-frequency loss compensation can play a critical role for optimal preemphasis setting; see Figure 7 where eye height is significantly improved if PWM-RC scheme is enabled.

The main disadvantage of proposed method lies in a problematic circuit realization. In $[10,11]$ it is possible to find the solutions for a raised-cosine signaling where only the conventional NRZ pulses are used. Future work will be focused on practical testing of proposed pulse shaping predistortion technique over the real band-limited transmission channel to verify the better method performance. To create the proposed PWM-RC signaling scheme, a softwareimplemented signal realization will be used.

\section{References}

[1] S. H. Hall and H. Heck, Advanced Signal Integrity for HighSpeed Digital Design, John Wiley \& Sons, Hoboken, NJ, USA, 2009.

[2] Y. Yuminaka and K. Yamamura, "Equalization techniques for multiple-valued data transmission and their application," in Proceedings of the 37th International Symposium on MultipleValued Logic (ISMVL '07), pp. 26-29, Oslo, Norway, May 2007.

[3] B. Ševčík and L. Brančík, "Time-domain pre-distortion technique using raised cosine shaping for high-speed serial signaling," ElectroScope, no. 4, pp. 1-6, 2011.

[4] J. H. R. Schrader, Wireline equalization using pulse-width modulation [Ph.D. thesis], 2007.

[5] B. Ševčík, L. Brančík, and M. Kubíček, "Analysis of preemphasis techniques for channels with higher-order transfer function," International Journal of Mathematical Models and Methods in Applied Sciences, vol. 5, no. 3, pp. 433-444, 2011.

[6] Y. Yuminaka, Y. Takahashi, and K. Henmi, "Multiple-valued data transmission based on time-domain pre-emphasis techniques in consideration of higher-order channel effects," in Proceedings of the 39th International Symposium on MultipleValued Logic (ISMVL '09), pp. 250-255, Okinawa, Japan, May 2009.

[7] J. Ulrych, "Problematika integrity signálů ve smíšených elektronických systémech," Vysoké učení technické v Brně, Fakulta elektrotechniky a komunikačních technologií, 71 s, Vedoucí diplomové práce doc. Ing. Lubomír Brančík, CSc, Brno, Czech Republic, 2007.

[8] B. Ševčík and L. Brančík, "Analysis and modeling of signal integrity problems in the serial communication devices," in Proceedings of the International Conference on Mathematical Models for Engineering Science (MMES '10), pp. 172-178, IEEE.AM, Canary Islands, Spain, November 2010.

[9] T. B. Wendemagegnehu and M. Aleksic, "A Study of Optimal Data Rates of High-Speed Channels," DesignCon 2011, Santa Clara, Calif, USA, 2011.

[10] R. Bashirullah, L. Wentai, and R. Cavin, "Cross-talk reduction for interconnect-limited bus based on raised cosine signaling," in Proceedings of the Interconnect Technology Conference, Burlingame, Calif, USA, 2001.

[11] Y. Yuminaka, "High-speed data transmission techniques using raised cosine signaling," Key Engineering Materials, vol. 459, pp. 252-259, 2011. 

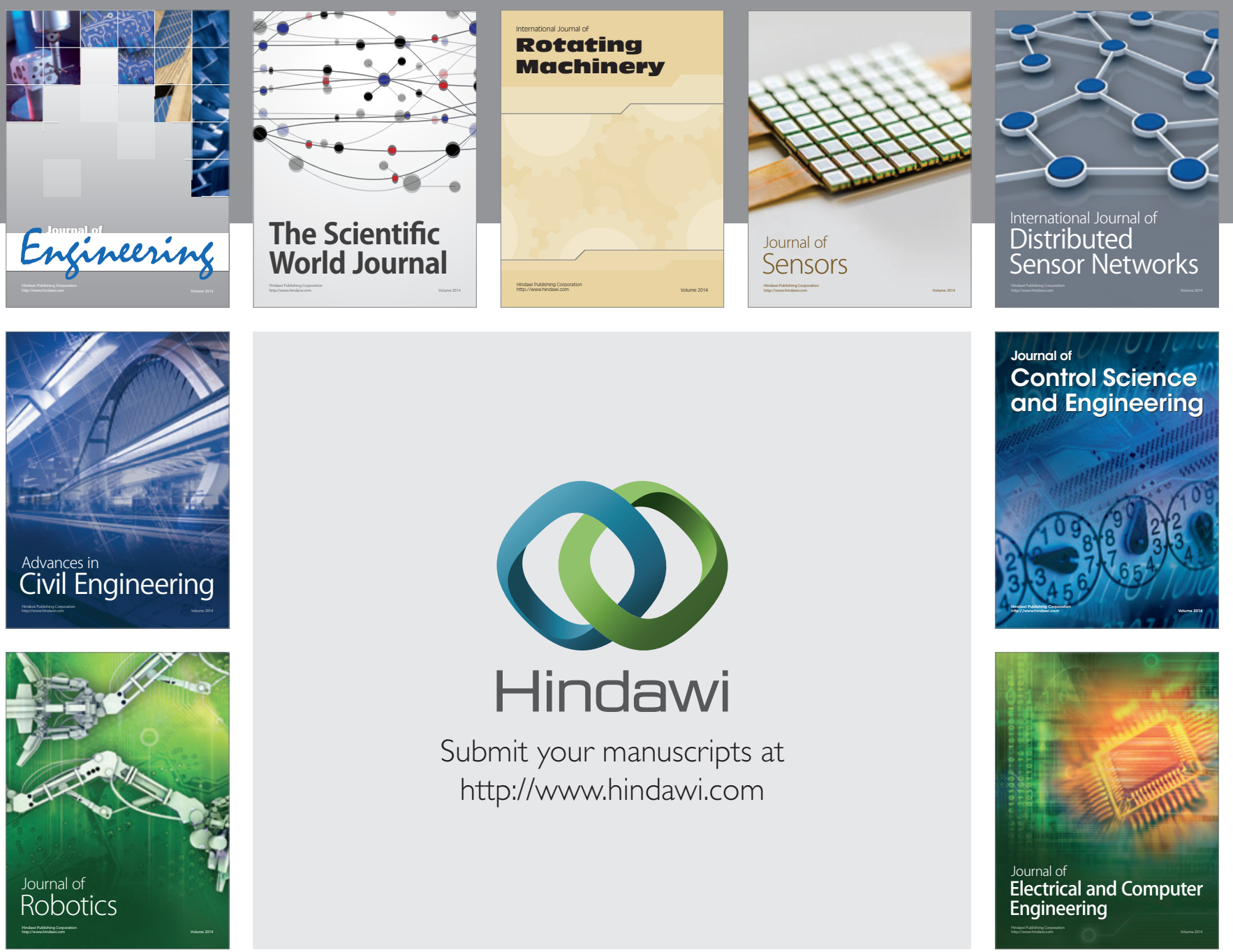

Submit your manuscripts at

http://www.hindawi.com
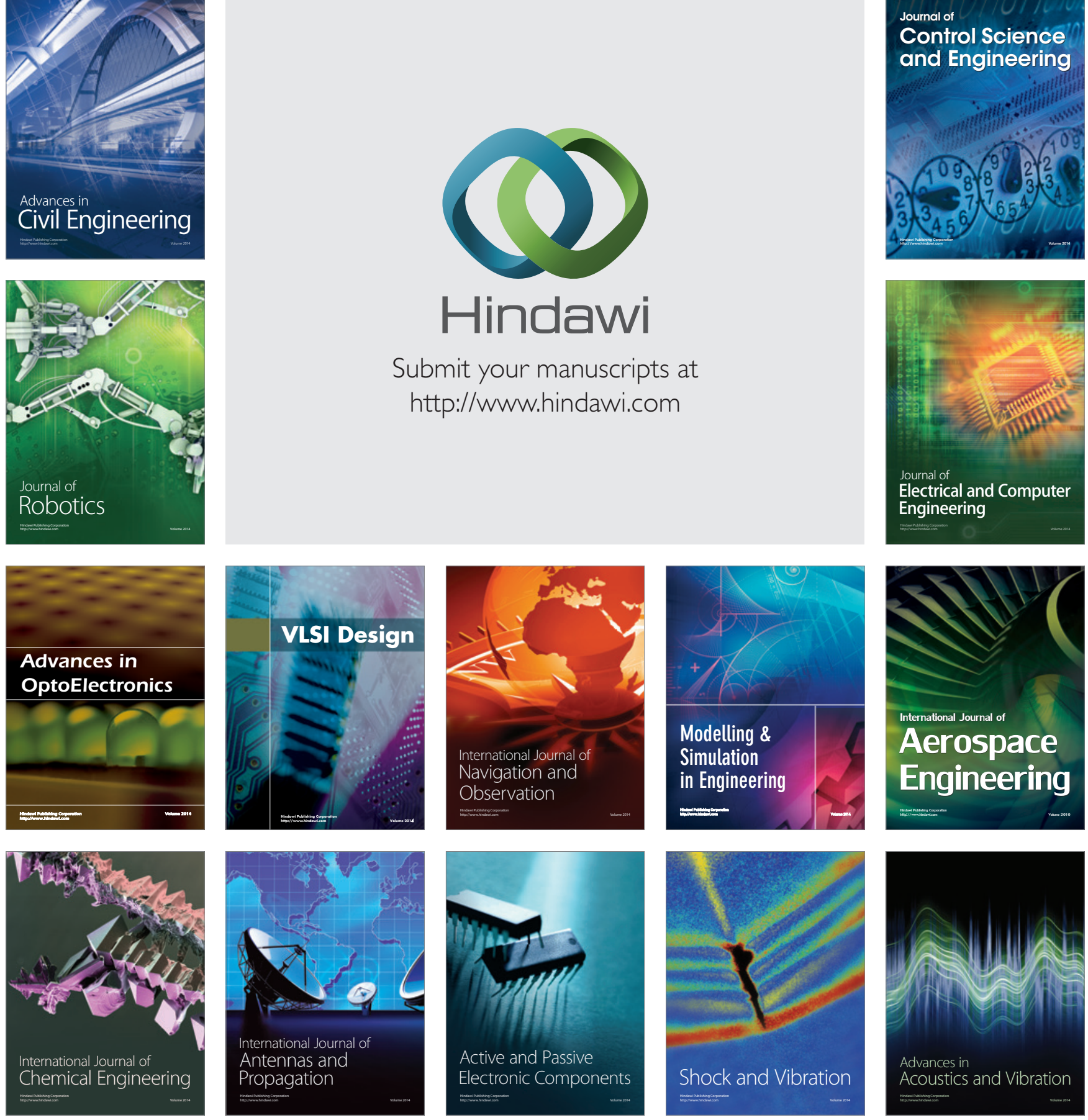